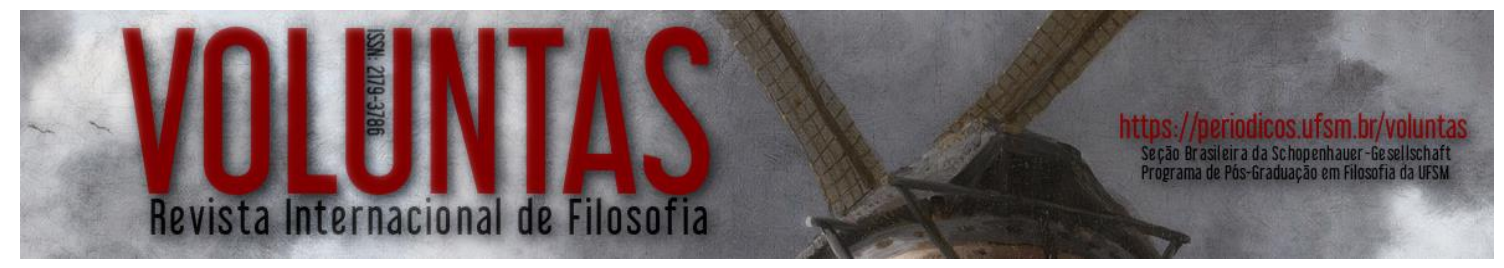

ISSN: 2179-3786

DOI: $10.5902 / 2179378635704$

\title{
A noção de Spielraum como fundamento para a Eudemonologia de Schopenhauer ${ }^{1}$
}

\author{
The notion of Spielraum as the foundation to the Schopenhauer's eudemonology
}

\author{
Leandro Chevitarese \\ Professor Associado I de Filosofia da UFRRJ \\ E-mail: leandrochevitarese@yahoo.com.br
}

Resumo: O conceito schopenhaueriano de "caráter adquirido" articula a dificuldade de fundamentar as condições de possibilidade de um tal aprendizado no curso da vida em face à recusa da liberdade empírica. Ainda que não se trate aqui certamente de Freibeit (Liberdade), por outro lado, não há por quê supor que não haja certo espaço de ação como condição de possibilidade para a sabedoria de vida. Deste modo, o artigo pretende investigar a noção de Spielraum (Espaço de manobra, Margem de ação) como chave de leitura para a proposta eudemonológica de Schopenhauer.

Palavras Chaves: Eudemonologia; Ética empírica; Liberdade.

Abstract: The schopenhauerian concept of "acquired character" articulates the difficulty to found the conditions of possibility of such a learning in lifetime before the refusal of the empirical freedom. Although it is certainly not about Freibeit (Freedom), on the other hand there is no need to suppose that a certain space of action as the condition of possibility to the Wisdom of Life does not exist. Thus, this article aims to examine the notion of Spielraum (Space of maneuvre, Margin of action) as a reading key to Schopenhauer's eudemonological proposition.

Key Words: Eudemonology; Empirical ethics; Freedom.

\section{Introdução}

vontade, essência do mundo, devora-se a si mesma. A inevitável dinâmica
do desejo nos apresenta a existência como sofrimento. Ninguém pode deixar
de ser o que é: não há livre-arbítrio. Somente a arte e a compaixão podem, talvez, redimir o sem sentido do mundo. Todavia, é possível ainda conquistar certa lucidez positiva de enfrentamento do mal de viver, tornando a vida menos infeliz. Este é o papel da eudemonologia de Schopenhauer, que se configura pela construção do caráter adquirido, o aprendizado que nos é possível no curso de vida.

Entretanto, tal formulação não é isenta de dificuldades. Como compreender efetivamente as possibilidades de tal aprendizado, em face da recusa schopenhaueriana à liberdade empírica? Em que termos devemos compreender as condições que tornam possível a edificação de uma sabedoria de vida? O presente

\footnotetext{
${ }^{1}$ Conferência apresentada no VIII Colóquio Internacional Schopenhauer, realizado em 2017, em Curitiba - PR. 
artigo pretende investigar a noção de Spielraum (espaço de manobra, margem de ação) como chave de leitura para compreensão do fundamento da eudemonologia de Schopenhauer.

$\mathrm{Na}$ estrutura que se segue, primeiramente serão apresentadas brevemente as concepções de caráter - inteligível, empírico e adquirido - na obra de Schopenhauer e algumas considerações sobre sua eudemonologia, com ênfase para a problemática do espaço de ação que seria próprio à sabedoria de vida. Em seguida, será elaborada uma abordagem mais específica da noção de Spielraum em sua articulação com a experiência do arrependimento (Reue), como forma de oferecer uma perspectiva de entendimento acerca das condições de possibilidade implícitas a construção do caráter adquirido, fundamento da eudemonologia de Schopenhauer.

\section{Considerações sobre o caráter inteligivel, empirico e adquirido}

A partir de distinções estabelecidas no idealismo transcendental kantiano, a noção de "caráter" assume uma significativa importância na obra de Schopenhauer. Pode-se mesmo dizer que o autor elabora uma complexa "caracterologia" $\mathrm{em}$ sua metafísica da vontade. Os atos de um homem são efeitos da ação de motivos sobre seu caráter, "nesse modo mesmo de agir manifesta-se seu caráter empírico, por seu turno, neste manifesta-se de novo seu caráter inteligível, a vontade em si, da qual ele é fenômeno determinado" (W I, \55, p. 372-373). O caráter inteligivel não se encontra submetido ao princípio de razão suficiente, sendo-lhe estranha toda e qualquer causalidade e, desse modo, deve ser compreendido como propriamente livre. Neste sentido, o que somos em essência, por meio de nosso caráter inteligível é simplesmente o que somos, sem qualquer causa ou razão, e nele repousa tudo aquilo que um indivíduo pode vir a fazer em sua existência. Aquilo que se demonstra expresso em sua conduta constituirá seu caráter empírico.

Como o caráter inteligível se encontra fora do tempo, permanecendo alheio a qualquer modificação, e o caráter empírico é apenas sua expressão ao longo da existência, tem-se que o caráter humano é concebido como imutável. Somente o caráter inteligível, uma vez que não está submetido à causalidade, pode ser compreendido como propriamente livre; já o caráter empírico permanece condicionado à causalidade própria a qualquer manifestação fenomênica. Pode-se dizer, nesse sentido, que há em Schopenhauer uma tentativa de conciliar liberdade e necessidade: "Cada coisa como fenômeno, como objeto, é absolutamente necessária; no entanto, em si mesma é vontade e esta é integralmente livre para toda a eternidade" (W I, \55, p. 372). Isso significa que o filósofo não recusa inteiramente a ideia de

\footnotetext{
2 Para uma análise cuidadosa desta problemática ver DEBONA, Um caráter abissal - a metafísica schopenhaueriana da Vontade como caracterologia.
} 
liberdade, apenas a desloca para um outro nível, distinto das ações humanas, pois a liberdade repousa exclusivamente no ser.

Ainda que seja fenômeno de uma vontade livre, presentificada no caráter inteligível, o caráter empírico se revela por meio de atos espaço-temporais que permanecem estranhos à liberdade: "nossos atos individuais de modo algum são livres; contudo, o caráter individual [inteligível] de cada um deve ser considerado como seu ato livre" (P II, S 116, trad. Payne p. 226, trad. Cacciola, p. 206). Todas as ações surgem necessariamente daquilo que se é, como manifestação livre da vontade. Mas, sendo o que somos, enquanto caráter inteligível, as manifestações daí decorrentes encontram-se condicionadas pelo princípio de causalidade. Cada indivíduo "é assim porque de uma vez por todas assim quer ser" (P II, \ 116, trad. Payne p.227, trad. Cacciola, p.206). Todavia, na medida em que é, não pode deixar de ser, e seus atos são uma consequência necessária de seu caráter inteligível. Só poderíamos querer diferentemente se tivéssemos outro caráter, ou seja, se fôssemos outra pessoa. Cada uma de nossas ações leva, inexoravelmente, nossa marca. Uma observação retroativa de todos os nossos atos pode apenas nos fazer conhecer o que somos.

O caráter é imutável e inato, mas ainda que "sempre sejamos as mesmas pessoas, nem sempre nos compreendemos" (W I, \55, p. 391). Esse conhecimento só pode ser produzido pela experiência de vida, visto que só conhecemos nosso caráter empírico através de nossos atos, temporalmente. Neste sentido, é possível constituir o que Schopenhauer denomina caráter adquirido (erworbenen Charakter), "O qual se obtém na vida pelo comércio com o mundo e ao qual é feita referência quando se elogia uma pessoa por ter caráter, ou se a censura por não o ter" (W I, \55, p. 391).

Este "autoconhecimento" de nossa natureza, obra do intelecto, não pode, no entanto, transformar a própria vontade, que lhe é anterior e constitui nosso ser. O intelecto é apenas o mediador pelo qual se dá a influência dos motivos sobre a vontade humana. Enquanto representações abstratas, os motivos não podem alterar o caráter; a eles, cabe tão somente "mudar a direção do seu esforço, noutros termos, fazê-la procurar o que inalteradamente procura por um caminho diferente do até então seguido" (W I, \55, p. 381). O papel da educação, por sua vez, restringe-se a demonstração de que usou mal seus meios para obter o que ansiava, visando alterar o encaminhamento dos esforços da vontade.

É importante destacar que a "modificabilidade do conhecimento e, por meio deste, do agir" (W I, $\int 55$, p. 381) é extremamente ampla. Ainda que o intelecto não possa transformar a vontade ou decidir em seu nome, pode ele, entretanto, contribuir para uma mudança na canalização de nossos esforços, alterando significativamente a conduta.

Para que se conquiste esse caráter adquirido, "um homem também precisa saber o que se quer, e saber também o que se pode fazer. Tão-somente assim mostrará 
caráter, para então poder consumar algo consistente" (W I, \55, p. 393). Conhecendo bem o que quer e o que pode, cada indivíduo tem a chance de "aprender a lidar com o que é”, evitando que se desgaste em tentativas inócuas, pressionando seu caráter além de suas possibilidades e aumentando com isso sua carga de sofrimento. E, em geral, vale frisar, tal amadurecimento só se faz através de muitos tropeços e equívocos.

A possibilidade do caráter adquirido evidencia a oportunidade de alterar, por meio do aprendizado, nosso encaminhamento na vida. Esse seria o exercício de um tipo de ação bem distante da noção de Freiheit (liberdade), mas que poderia ser melhor compreendida através da noção de Spielraum (espaço de manobra), esta seria uma "liberdade de ser o que se é", como veremos adiante.

Para que se efetive tal caráter adquirido, "um homem também precisa saber o que se quer, e saber também o que se pode fazer. Tão-somente assim mostrará caráter, para então poder consumar algo consistente" (W I, \55, pp. 392-393). O exercício do autoconhecimento torna-se imprescindível para a efetivação de tal caráter, o que significa conhecer seu próprio querer, bem como as possibilidades que lhe são efetivas no curso de vida.

Schopenhauer sugere que nossa conduta pode variar amplamente em função do caráter adquirido: "O conhecimento de nossa mente, com suas faculdades de todo o gênero e limites inalteráveis, é, nesse sentido, o caminho mais seguro para obtermos o maior contentamento possível conosco" (W I, \55, p. 395). A conquista de tal caráter é o que torna possível a perspectiva eudemonológica presente na obra do filósofo.

\section{Considerações sobre a Eudemonologia}

A Eudemonologia de Schopenhauer configura-se, na verdade, como um eufemismo. Consiste na arte de ser feliz o quanto nos é possível, ou ainda, na arte de fazer consigo o melhor possível para uma vida menos infeliz. Investiga-se o que se pode fazer em prol de uma vida melhor, uma espécie de "pedagogia da felicidade possível". Embora seus fundamentos já se encontrem apresentados no parágrafo 55 de O Mundo como Vontade e como Representação, o desenvolvimento mais significativo de sua eudemonologia é apresentado em Aforismos para Sabedoria de Vida (1851).

Concebendo três divisões fundamentais que estabeleceriam "a diferença na sorte dos mortais" (A, p. 3), Schopenhauer trata daquilo que alguém é, daquilo que alguém tem e daquilo que alguém representa. Sem dúvida, em sua argumentação, "o que alguém é e tem em si mesmo, ou seja, sua personalidade e o seu valor, é o único contributo imediato para sua felicidade e para seu bem-estar" (A, p. 15). Em seguida, apresenta suas 53 máximas para a Sabedoria de Vida, que se dividem em quatro seções: (1) máximas gerais; (2) máximas referentes à nossa conduta em relação a nós mesmos; 
(3) máximas que concernem à nossa conduta para com os outros; (4) máximas que se aplicam à nossa conduta em relação ao curso do mundo e ao destino.

Segundo o filósofo, a "regra suprema" de toda a sabedoria de viver pode ser encontrada na obra de Aristóteles: "O prudente aspira não ao prazer, mas à ausência de dor" (A, p. 140). Tendo como alicerce a metafisica da vontade que nos ensina que "toda a vida é sofrimento (Alles Leben Leiden ist)" (W I, \56, p. 400), Schopenhauer sinaliza a possibilidade de mitigar tal condição por uma reorientação de nossos esforços, advinda de uma melhor compreensão da inutilidade e do vazio que é próprio à realização dos desejos. Somente a insensatez pode justificar a busca incessante do desfrute de prazeres às custas de intensos sofrimentos. Perseguir uma "felicidade positiva" é como se lançar indefinidamente ao deserto, na esperança de chegar à miragem produzida pela insolação. Deste modo, tal possibilidade de uma vida menos infeliz é assim definida: "se a um estado sem dor ainda couber a ausência de tédio, então a felicidade terrena foi em essência alcançada; o resto é quimera” (A, p. 142).

A segunda seção de máximas aborda a nossa conduta em relação a nós mesmos. Schopenhauer inicia essa seção de máximas apresentando sua tradução da proposta grega clássica do "autoconhecimento": o indivíduo "precisa saber principalmente e antes de tudo o que em verdade quer. (...) Precisa também reconhecer em geral qual é sua vocação, o seu papel e a sua relação com o mundo" (A, p. 153). Assim procedendo, cada um poderia melhor investir em seus potenciais, evitando caminhos desfavoráveis às predisposições de seu caráter. Parece claro que tal proposta de "conhece-te a ti mesmo" não pode prescindir da aceitação daquilo que se é. Não se trata apenas de conhecer, é preciso ver com clareza e aceitar limitações e dificuldades, bem como reconhecer potencialidades e qualidades.

Essa vida estrategicamente pensada e exercitada, não pode prescindir de uma constante disciplina intelectual. Schopenhauer afirma, por exemplo, que não se deve considerar, em relação a um evento infeliz ou desgraça que nos suceda, que tal acontecimento poderia ser diferente. Deve-se, com efeito, considerar que "tudo o que acontece, acontece necessariamente; vale dizer, é inevitável" (A, p. 182). Entretanto, o recurso estratégico ao "ponto de vista fatalista" não é, para Schopenhauer, uma regra aplicável em todos os casos. Particularmente, quando diante de um arrependimento, decorrente de nossa negligência ou imprudência, então, "a ponderação repetida e dolorosa de como se poderia ter impedido a infelicidade é uma autoexpiação salutar para nossa experiência e melhoria e, assim, para o futuro" (A, p. 182).

No que se refere às máximas que concernem à nossa conduta para com os outros, terceira seção das máximas de ASV, Schopenhauer destaca que para o bemviver, sem dúvida, é preciso uma boa dose de "precaução e indulgência" (A, p. 199), a fim de evitar prejuízos tolos e disputas desagradáveis. A convivência nos exige um esforço constante de tolerância em relação aos outros. Acima de tudo, não se deve condenar de modo incondicional nenhuma individualidade: "para vivermos entre os homens 
temos de deixar cada um existir como é, aceitando-o em sua individualidade ofertada pela natureza, não importando qual seja" (A, p. 200). Nisso repousa a sabedoria do provérbio "viver e deixar viver". Aceitar o outro significa também se permitir vê-lo como de fato é, sem justificativas ou pseudo-explicações que procurem ocultar sua natureza tal como se mostra em seus atos. Enxergando com clareza, é possível uma maior lucidez em nossas ações para com os outros. É preciso reconhecer e aceitar o caráter nefasto e egoísta da maioria dos homens, "companheiros de infortúnio", pelo que pode se fortalecer em nós a tolerância no trato com nossos semelhantes. Como Schopenhauer destaca em outro trecho de Parerga e Paralipomena:

De fato, a convicção de que o mundo, e, portanto, também o homem, é algo que propriamente não deveria ser, é adequada a nos prover de tolerância uns em relação aos outros: pois o que há de se esperar de seres sob tais predicamentos? E mesmo partindo desse ponto de vista, poderse-ia perguntar que o tratamento apropriado entre os homens, em lugar de Monsieur, Sir etc., deveria ser "companheiro de infortúnio" [...]. Por mais estranho que possa parecer, corresponde à coisa, lança sobre o outro a luz apropriada e recorda o necessário, a tolerância, paciência, piedade, amor ao próximo, indispensável a todos, e portanto de que todos são devedores (P II, \156, trad. Payne, p. 304, trad. Cacciola p. 225).

Cabe a nós aprender a lidar com cada individualidade da melhor maneira possível, com tolerância, sem esperar muito de ninguém, aproveitando de cada um o que ele tem de melhor.

Pode-se observar que problemática da singularidade do caráter é fundamental para a efetivação da Sabedoria de Vida. Ainda que todos sejamos vontade, cada caráter é individual e traz consigo sua própria complexidade, contradições e impulsos conflitantes. Acima de tudo parece crucial para Schopenhauer considerar que, ainda que a presença de certas disposições no caráter inato favoreça ou prejudique a efetivação de alguma sabedoria ao longo da vida, deve-se enfatizar que a qualquer um cabe certa lapidação no caráter. "Nenhum caráter é de tal modo talhado que possa ser abandonado a si mesmo, vagueando incerto daqui para acolá, mas cada um precisa ser guiado por conselhos e máximas" (A, p. 215). Esse aprimoramento corresponde ao caráter adquirido e não pode prescindir de um certo espaço de ação que permita tal direcionamento.

$\mathrm{Na}$ última seção de máxima, Schopenhauer propõe três alegorias sobre o destino em Aforismos para Sabedoria de Vida. A primeira delas é a seguinte:

O destino [...] desempenha o papel do vento que nos impele rapidamente para adiante, ou para trás, sendo nossos esforços e nossos empenhos de muito pouca serventia. Estes desempenham o papel dos remos: quando, depois de muitas horas de trabalho, fizeram-nos avançar no percurso, uma súbita rajada de vento faz-nos regredir o mesmo tanto. Ao contrário, se 
este último é favorável, avançamos de tal modo que nem precisamos dos remos (A, p. 233).

Parece claro que o bom êxito de nossos esforços pessoais (os remos), ou ainda a conquista de certa sabedoria de vida, permanece condicionado às possibilidades ofertadas pela sucessão de acontecimentos, ou destino (o vento). Por outro lado, em condições climáticas minimamente favoráveis, persiste significativo espaço de ação (ou espaço de manobra - Spielraum), pelo uso de nossos remos.

As outras duas alegorias referem-se a dinâmica que é própria aos jogos: "O destino embaralha as cartas, e nós jogamos" (A, p. 234), ou ainda: "na vida as coisas acontecem como no jogo de xadrez: esboçamos um plano que, todavia, fica condicionado à vontade do adversário, no jogo, e à do destino, na vida” (A, p. 235). Em ambos os casos, reforça-se a concepção de que há um espaço de possibilidades de ação circunscrito, não somente pelo caráter, mas também pelas condições em que a vida nos é apresentada.

Estas são importantes pistas para compreender as condições de possibilidade para a efetivação do caráter adquirido, que pode viabilizar uma vida menos infeliz. O aprendizado no curso de vida - como também nos jogos aqui apresentados como alegoria - só se torna possível através de inúmeros ensaios e tentativas, através de rudes fracassos. Por meio deles, enfrentando o sofrimento que lhes é implícito, podese corrigir a conduta e, parece-me, o elemento fundamental para uma melhor compreensão de tal processo encontra-se presente na experiência do arrependimento. Vejamos.

\section{Sobre o Arrependimento (Reue) e o Espaço de Manobra (Spielraum³)}

Antes de considerar propriamente o arrependimento e seu papel na construção do caráter adquirido, cabe distingui-lo de outro fenômeno da consciência moral analisado por Schopenhauer: o remorso (Gewissensangst) 4 .

O filósofo concebe o remorso como uma "dor sobre o conhecimento de nosso si mesmo, ou seja, como vontade. Baseia-se na certeza de que sempre temos a mesma vontade" (W I, \55, p. 384). Este sentimento de mal-estar advindo de nossa consciência moral caracteriza-se pelo reconhecimento, com certo horror, de que fizemos o que queríamos fazer, ou seja, realmente fez-se em ato o que repousava na

\footnotetext{
${ }^{3}$ Para uma aproximação entre Schopenhauer e Nietzsche a partir da noção de Spielraum, ver PASCHOAL, Entre a caracterologia de Schopenhauer e o tornar-se o que se é de Nietzsche, 2016. Para uma articulação entre o princípio cínicoestóico de "conversão a si mesmo" e a noção de Spielraum em Schopenhauer, ver CHEVITARESE, Schopenhauer e os Cínicos: Elementos do cinismo na eudemonologia schopenhaueriana, 2012.

${ }^{4} \mathrm{O}$ termo que Schopenhauer emprega, Gewissensangst, poderia ser traduzido por "consciência moral angustiada", ou como prefere Jair Barboza, "Peso de consciência" (Cf. Nota 20, W I, \55, p. 384). Optei aqui por traduzir por "remorso", acompanhando a tradução francesa de Burdeau, revisada por Roos, indicada na bibliografia, por considerar que o termo expressa mais imediatamente em língua portuguesa o sentimento a que se refere o filósofo.
} 
essência de nosso ser como vontade. Mas o que se fez produziu intenso sofrimento: eis o remorso. Em MVR \62, quando Schopenhauer aborda o tema da justiça e do direito, acrescenta-se que o remorso é o sentimento proveniente da injustiça cometida. Por fim, MVR \65, ao analisar o significado essencial do mal praticado, o filósofo observa que "como sentimento - ou seja, não como conhecimento claro, abstrato constitui o conteúdo do peso de consciência [remorso]" (W I, $\int 65$, p. 468).

$\mathrm{O}$ arrependimento (Reue) recebe um tratamento muito diferenciado por parte de Schopenhauer, e tal distinção mostra-se fundamental para os propósitos do presente artigo. Observa-se que o arrependimento:

\begin{abstract}
nunca se origina de a Vontade ter mudado (algo impossível) mas de o conhecimento ter mudado [...]. Portanto nunca posso me arrepender do que quis, mas sim do que fiz, visto que, conduzido por falsas noções, agi de maneira diferente daquela adequada à minha vontade. $\mathrm{O}$ arrependimento é a intelecção disso por via de um conhecimento mais preciso. E isto se estende não só a sabedoria de vida, à escolha dos meios, ao julgamento do mais adequado fim à minha vontade, mas também ao ético propriamente dito (W I, $₫ 55$, p. 383).
\end{abstract}

É a partir do sofrimento que se pode, talvez, promover o caráter adquirido. $\mathrm{O}$ arrependimento, por sua vez, é o entendimento de que o indivíduo se conduziu em desacordo com a sua vontade, o que permite encontrar um modo de vida mais adequado, reajustando sua conduta em sintonia com a construção de uma Sabedoria de Vida. Caso isso torne-se efetivo, certamente pode-se evitar novos arrependimentos. Pois nem sempre o homem compreende bem seu caráter,

que se manifesta apenas no tempo, isto é, via ações, encontra uma resistência análoga no conhecimento, que quase nunca lhe fornece os dados inteiramente corretos, fazendo o ato não corresponder de maneira precisa e integral à Vontade, preparando dessa forma o arrependimento (W I, $\int 55$, p. 384).

$\mathrm{O}$ arrependimento surge por uma inadequação do querer em relação às ações cometidas. Ele exige uma correção da relação estabelecida entre um ato e sua efetiva intenção. Como destaca Cacciola, na medida em que o conhecimento abstrato faz surgir "hesitação e incerteza", advém a "possibilidade do erro, que pode falsear as manifestações da vontade por meio de motivos aparentes que, nem por isso, deixam de ser eficazes" 5 .

No segundo tomo de MVR, no Capítulo XLVIII, intitulado "A Propósito da Ética", ou "Sobre a Ética", Schopenhauer retoma a questão do arrependimento de um modo bastante interessante, que nos permite desenvolver melhor a compreensão de tal conceito e suas relações com a Sabedoria de Vida e a Eudemonologia. Em uma

\footnotetext{
${ }^{5}$ CACCIOLA, Schopenhauer e a questão do dogmatismo, p. 168.
} 
passagem específica (SW, II, p. 679), ao tratar do tema, surge a noção de Spielraum, que optei aqui neste artigo por traduzir como "espaço de manobra", ou "margem de ação". Reproduzo o referido texto original e, na sequência, contraponho as duas traduções disponíveis atualmente em português:

Eine moralische Reue ist nun dadurch bedingt, daß, vor der That, die Neigung zu dieser dem Intellekt nicht freien Spielraum ließ, indem sie ihm nicht gestattete, die ihr entgegenstehenden Motive deutlich und vollständig ins Auge zu fassen, vielmehr ihn immer wieder auf die zu ihr auffordernden hinlenkte. Diese nun aber sind, nach vollbrachter That, durch diese selbst neutralisirt, mithin unwirksam geworden. Jetzt bringt die Wirklichkeit die entgegenstehenden Motive, als bereits eingetretene Folgen der That, vor den Intellekt, der nunmehr erkennt, daß sie die stärkern gewesen wären, wenn er sie nur gehörig ins Auge gefaßt und erwogen hätte. Der Mensch wird also inne, daß er gethan hat, was seinem Willen eigentlich nicht gemäß war: diese Erkenntniß ist die Reue. Denn er hat nicht mit völliger intellektueller Freiheit gehandelt, indem nicht alle Motive zur Wirksamkeit gelangten (SW, II, p. 679, grifo nosso).

Um arrependimento moral é condicionado pelo fato de antes do ato, a inclinação para este não deixar ao intelecto espaço de manobra, na medida em que não lhe permite apreender distinta e completamente os contramotivos do ato, mas antes reconduz sem cessar o intelecto aos motivos favorecem o ato. Estes motivos, entretanto, após o ato consumado, são neutralizados pelo mesmo ato, portanto, tornam-se ineficazes. Agora a realidade traz diante do intelecto os motivos opostos, como consequências reais recém-advindas do ato praticado, com o que o intelecto doravante reconhece que estes motivos poderiam ter sido mais fortes se ele os tivesse apreendido e ponderado convenientemente. A pessoa torna-se então, ciente, de que o que ela praticou não era propriamente conforme sua vontade: esse conhecimento é o arrependimento. Pois a pessoa não agiu com plena liberdade intelectual, na medida em que nem todos os motivos chegaram a atuar (W II, XLVIII, trad. Jair Barbosa, p. 708, grifo nosso).

Um arrependimento moral [Reue] está condicionado, pelo fato de que, antes da realização do ato, alguém que se vê arrastado por uma inclinação não deixa o intelecto atuar livremente, uma vez que não lhe permite contemplar clara e completamente os motivos opostos à ação, mas, dirigeo de novo e de novo aos motivos que incitam ao ato. Mas agora, quando a ação é feita, estes motivos são neutralizados por este mesmo fato em si, e, consequentemente, tornam-se ineficazes. Agora a efetividade traz os motivos conflitantes diante do intelecto como consequências do ato que já aconteceu, e o intelecto, então, sabe então que eles teriam sido mais fortes, caso lhe fosse possível contemplar devidamente e ponderado cuidadosamente sobre cada um deles. O homem, portanto, torna-se consciente de ter feito o que não era realmente de acordo com a sua vontade, o conhecimento traz arrependimento. Porque ele não agiu com plena liberdade intelectual, uma vez que nem todos os motivos atingiram a eficácia (W II, XLVIII, trad. Eduardo Fonseca, pp. 322-323, grifo nosso). 
Parece claro que o Spielraum é uma possibilidade disponível ao intelecto que, quando suprimida por uma forte inclinação, conduz o indivíduo a uma ação distinta daquela que melhor encontra sintonia com sua própria vontade. $\mathrm{Na}$ primeira tradução apresentada, de Barboza, observa-se a opção pela expressão "espaço de manobra" para traduzir Spielraum. Na segunda versão, de Fonseca, opta-se pela tradução "atuar livremente", ainda que o contexto da frase esclareça perfeitamente que se trata de uma “atuação livre" no sentido de ofertar ao caráter motivos opostos à ação. É interessante observar que o arrependimento se instaura na medida em que, tendo sido realizado o ato, os motivos que conduziram a ação são neutralizados, e aqueles que não tinham sido devidamente apresentados pelo intelecto fazem-se presentes a partir das consequências efetivas do ato cometido.

A consciência moral que é própria ao arrependimento se instaura por que o intelecto é capaz de compreender que, caso ele tivesse sido capaz de atuar em seu Spielraum, a ação não teria sido realizada e suas consequências nocivas não teriam tomado lugar. Um melhor desempenho no que se refere à capacidade do intelecto em sugestionar à vontade teria, portanto, evitado o sofrimento que agora se faz presente. E vale lembrar aqui a conhecida metáfora de Schopenhauer sobre a relação entre intelecto e vontade: "a comparação mais notável para relação entre ambos é a do forte cego que carrega nos ombros o paralítico que vê" (W II, XIX, trad. Jair Barboza, p. 253). Ainda que o intelecto paralítico nada possa decidir, e ainda que a vontade cega e forte jamais enxergue, isto não significa que ela seja surda. Se o intelecto paralítico souber operar em seu Spielraum, pode melhor sugestionar à vontade cega, uma vez que seja capaz de conhecer seu caráter, apresentando os contramotivos suficientes para evitar a realização de atos que provavelmente acarretariam sofrimento e arrependimento.

Pode-se dizer que um dos propósitos da eudemonologia de Schopenhauer é evitar o arrependimento daqueles que querem minimizar o sofrimento. Trata-se aqui de um elemento importante. Não se pode decidir o que se quer (Velle non discitur). A proposta eudemonológica só pode fazer sentido caso se queira viver melhor. Neste caso, é possível usar o Spielraum que é próprio ao intelecto para sugestionar de modo mais adequado à vontade, a partir do que foi aprendido pelo intelecto diante do sofrimento ao longo da existência.

A perspectiva eudemonológica parece ser, acima de tudo, um convite a essa tentativa, um convite ao enfrentamento positivo da vida e do sofrimento a ela implícito. Por meio de uma vida estrategicamente pensada e exercitada, talvez seja possível conquistar uma melhor sabedoria e uma vida menos infeliz. 


\title{
5. Considerações finais
}

Pela metafísica da vontade compreende-se a imutabilidade do caráter, bem como a inexorabilidade de que todas as nossas ações são decorrências dele, mas é fundamental que o caráter seja percebido com a complexidade e contradição que lhe são inerentes. $\mathrm{O}$ aprendizado que é possível ao intelecto cria uma margem de ação para sugestionar diferenciadamente o caráter. Deste modo, torna-se possível uma conduta mais prudente, evitando o sofrimento, o arrependimento e procurando uma vida "menos infeliz". A capacidade de melhor explorar este espaço de manobra [Spielraum] viabiliza o "aprender a lidar com o que se é". Eis o fundamento da eudemonologia e da Sabedoria de Vida de Schopenhauer.

\begin{abstract}
Somente o conhecimento exato do seu caráter empírico concede ao homem aquilo que se chama o caráter adquirido: aquele que o possui conhece com exatidão as suas qualidades pessoais, tanto as boas quanto as más, sabendo, portanto, o que pode esperar ou exigir de si mesmo. A partir de então, ele pode interpretar seu papel [...] com arte e método, firmeza e conveniência" (E I, p. 101, grifo nosso).
\end{abstract}

Como afirma Gardiner, "Schopenhauer se refere a este homem como um grande ator"' que, reconciliado com seu papel, agindo em sintonia com aquilo que lhe é próprio, descobre a melhor forma de interpretar a si mesmo na tragédia de sua existência. Neste sentido, acertam Carvalho e Costa quando afirmam que seria melhor compreender o estatuto dos Aforismos para Sabedoria de Vida como "performático"7, como um convite a uma melhor forma de atuar nas relações e na sociedade, sinalizando também uma preocupação com a civitas.

O Spielraum é também o palco em que pode atuar com sabedoria aquele que quer descobrir a melhor forma de interpretar o drama que lhe cabe em sua existência. É preciso um certo espaço cênico de possibilidades para ser um melhor ator na tragédia que nos cabe encenar. É preciso compreender a proposta eudemonológica de Schopenhauer como um convite a uma Sabedoria Teatral. Neste palco, neste espaço cênico, neste espaço de manobra, enfim, neste Spielraum, encontra-se uma das condições fundamentais da eudemonologia de Schopenhauer. Por fim, pode-se dizer que, ainda o Spielraum jamais se constitua como Freiheit, por outro lado, fundamenta a possibilidade de exercício da "liberdade de ser o que se é" no teatro da existência.

\footnotetext{
${ }^{6}$ GARDINER, Schopenhauer, p. 387.

${ }^{7}$ CARVALHO; COSTA, Cai a cortina, misturam-se os papéis: desencontros e reencontros entre Schopenhauer e Nietzsche, pp. 358-359.
} 


\section{Referências bibliográficas}

CACCIOLA, M. L. M. O. Schopenhauer e a questão do dogmatismo. São Paulo: Edusp, 1994.

CARVALHO, R.; COSTA, G. "Cai a cortina, misturam-se os papéis: desencontros e reencontros entre Schopenhauer e Nietzsche". In: CARVALHO, R.; COSTA, G; MOTA, T. (Orgs.) Nietzssche-Schopenhauer: ecologia cinza, natureza agônica. Fortaleza: Ed. UECE, 2013.

CHEVITARESE, L. Schopenhauer e os Cínicos: Elementos do cinismo na eudemonologia schopenhaueriana. Revista Voluntas: Estudos sobre Schopenhauer, Vol. 3, Números 1 e $2-1^{\circ}$ e $2^{\circ}$ semestres de 2012.

DEBONA, V. Um caráter abissal - a metafísica schopenhaueriana da Vontade como caracterologia. Revista Voluntas: Estudos sobre Schopenhauer, Rio de Janeiro, Vol. 4, No 1, $1^{\circ}$ semestre de 2013, pp. 33-65.

GARDINER, P. Schopenhauer. México: Fondo de Cultura Económica, 1997.

PASCHOAL, A. E. Entre a caracterologia de Schopenhauer e o tornar-se o que se é de Nietzsche. Revista Voluntas: Estudos sobre Schopenhauer. Rio de Janeiro, Vol. 7, No 1 , $1^{\mathrm{o}}$ semestre de 2016, pp. 57-73.

SCHOPENHAUER, A. Die Welt als Wille und Vorstellung. Sämmtliche Werke. Textkritisch bearbeitet und herausgegeben von Wolfgang Frhr. von Löhneysen. Frankfurt am Main: Suhrkamp, 1986.

SCHOPENHAUER, A. Le Monde comme Volonté et comme Représentation. Trad. A. Burdeau (nouv. éd. rév. et corr. par R. Roos). Paris: Press Universitaires de France,

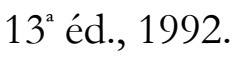

SCHOPENHAUER, A. O Mundo como Vontade e como Representação. Trad. Jair Barbosa. SP: UNESP, 2005.

SCHOPENHAUER, A. O Mundo como Vontade e como Representação. Tomo II. Trad. Jair Barbosa. SP: UNESP, 2015.

SCHOPENHAUER, A. O Mundo como Vontade e Representação. Tomo II. Trad. Eduardo Ribeiro Fonseca. Curitiba: Ed. UFPR, 2014, 2 vol.

SCHOPENHAUER, A. Parerga and Paralipomena. Trad. E. F. J. Payne. Vol. I e II. New York: Oxford University Press, 2000.

SCHOPENHAUER, A. Parerga e Paralipomena. Trad. M. L. M. O. Cacciola. São Paulo: 
Nova Cultural. 1988. (Coleção Os Pensadores).

SCHOPENHAUER, A. Aforismos para a sabedoria de vida. Trad. Jair Barboza. São Paulo: Martins Fontes, 2002.

SCHOPENHAUER, A. Essai sur le Libre Arbitre [Preisschrift über die Freiheit des Willens]. Trad. Salomon Reinach. Paris: Librarie Félix-Alcan, 1913.

Recebido: $19 / 11 / 18$

Received: $11 / 19 / 18$

Aprovado: 21/11/18

Approved: 11/21/18 